\title{
Isoflurane alone versus small dose propofol with isoflurane for removal of laryngeal mask airway in children-a randomized controlled trial
}

\author{
Dileep Kumar, Gauhar Afshan, Muhammad Zubair, Mohammad Hamid
}

\begin{abstract}
Objective: To compare the safety of laryngeal mask airway removal using two different deep anaesthesia techniques in paediatric patients.

Methods: The Randomized Control Trial was conducted at Aga Khan University Hospital, Karachi, from April 2012 to November 2013, and comprised patients aged 2-10 years scheduled for infraumbilical surgeries. Anaesthesia was induced with sevoflurane and later it was maintained by isoflurane, oxygen and nitrous oxide. The laryngeal mask airway was removed in the intervention group-I at 0.4 minimum alveolar concentration of isoflurane with propofol $1 \mathrm{mg} / \mathrm{kg}$. In the control group-II, it was removed at 1.2 minimum alveolar concentration of isoflurane alone. SPSS 19 was used for data analysis.
\end{abstract}

Results: Of the 50 patients, there were $25(50 \%)$ in each of the two groups. Overall, there were $46(92 \%)$ males and 4(8\%) females. Incidence of airway obstruction and teeth clenching was significantly higher in group-II ( $p<0.05$ each). Emergence duration was also significantly increased in group-II compared to group-I ( $p=0.001)$. The Post-Anaesthesia Care Unit stay timing was not significantly different between the groups $(p=0.74)$.

Conclusion: Laryngeal mask airway removal under deep anaesthetic technique of low-dose propofol with isoflurane was found to be associated with minimal adverse airway events than isoflurane alone in paediatric patients.

Keywords: Laryngeal mask airway, General anaesthesia, Propofol, Isoflurane, Airway obstruction, Emergence, Paediatric. (JPMA 69: 1596; 2019). doi: 10.5455/JPMA.296240.

\section{Introduction}

In anaesthetic practice from its invention till this modern era, the process of laryngeal mask airway (LMA) has a significant role. It is widely used for controlling the airway in paediatric surgical patients. ${ }^{1}$ The inventor and manufacturer formerly recommended LMA removal when the patient is fully awake and protective airway reflexes are regained. ${ }^{2}$ However, these recommendations were made and practised for adults because LMA was not in practice for paediatric patients in those days. ${ }^{3}$ Paediatric airway management is more challenging than adults due to anatomical and physiological variations. 4 In paediatric patients, LMA has great acceptance. However, the complication rate was remarkable with awake LMA removal in paediatrics. 4,5 There has been extensive research work done in the last decade which concludes that the process of LMA removal is completely Department of Anesthesia, Aga Khan University, Karachi, Pakistan. Correspondence: Dileep Kumar. e-mail: dileep.kumar@aku.edu safe under anaesthetic protocols. Some studies reported awake LMA removal is a better option, causing minimal risk of airway obstruction and negligible risk of aspiration ${ }^{5,6}$ whereas a few other studies have reported no difference in awake or deep LMA removal.7,8 However, the majority of studies tend to agree that deep LMA removal is safer for the paediatric population due to nominal risk for coughing, breath-holding, laryngospasm and bronchospasm.9-11 Intact airway reflexes, unobstructed airway, smooth emergence and faster recovery timing after $L M A$ removal are still challenges for paediatric patients. A combination of a small dose of propofol with isoflurane minimum alveolar concentration (MAC) awake would provide an ideal condition for safe LMA removal in paediatric patients.

The current study was planned to compare safe LMA removal under deep isoflurane anaesthesia versus a combination of small dose of propofol with isoflurane awake paediatric patients. 


\section{Patients and Methods}

The Randomized Control Trial was conducted at Aga Khan University Hospital (AKUH), Karachi, from April 2012 to November 2013. After obtaining approval from the institutional review board, the protocol was registered at ClinicalTrials.gov NCT01958138. with due parental consent, children with American Society of Anaesthesiologists (ASA) grade I and II aged 2-10 years planned for elective infra-umbilical surgery were enrolled using consecutive sampling method. Patients with known asthma, recent upper airway infection, facial abnormalities, and gastro-oesophageal disorder were excluded.

The sample size was calculated at the power of $80 \%$ and level of significance $5 \%$ to discover the difference of $40 \%$ among the groups. The calculation was based on clinical experience and it was assumed that the incidence of adverse airway events will be decreased by $70 \%$ in the interventionn group and $30 \%$ in the control group. All the subjects were pre-medicated with oral midazolam $0.3 \mathrm{mg} / \mathrm{kg}$, about $45-60$ minutes prior to the induction of anaesthesia. Once the standard monitors were applied, the baseline vitals were recorded. General anaesthesia was induced by an inhaled technique using sevoflurane $8 \%$ dial volume in oxygen via Mapleson F circuit. Once the child was asleep, the sevoflurane dial was dropped down up to $4 \%$ and an intravenous (IV) line was started and LMA was placed after confirming adequate jaw relaxation. LMA $\left(\mathrm{Ambu}^{\circledR}\right.$ AuraOnce $^{\mathrm{TM}}$ ) sizes were determined as per the manufacturer's recommendation (1.5 LMA size for 5-10kg; size 2 for 10-20kg; and size 2.5 for $20-30 \mathrm{~kg}$ ). Sevoflurane was replaced by isoflurane in $60 \%$ nitrous oxide and $40 \%$ oxygen for the maintenance of anaesthesia. The end-tidal carbon dioxide at 35$45 \mathrm{mmHg}$ and isoflurane MAC at 1.2 (Primus ${ }^{\circledR}$ Drager anaesthesia machine, Germany) in expiratory gases were maintained to standardise the anaesthetic depth. Spontaneous breathing was maintained in all children; $2 \mathrm{~L}$ gas flow was kept in circle system for the maintenance phase and $8 \mathrm{~L}$ flow via maples F circuit were kept for induction and emergence phase of anaesthesia. Caudal analgesia was administered in both the groups. Bupivacaine $2 \mathrm{mg} / \mathrm{kg}$ was diluted in normal saline and total injected caudal volume was calculated by $1 \mathrm{ml} / \mathrm{kg}$ of body weight. Once the surgery finished, patients were assigned into the study groups according to computergenerated random number table (Figure 1).

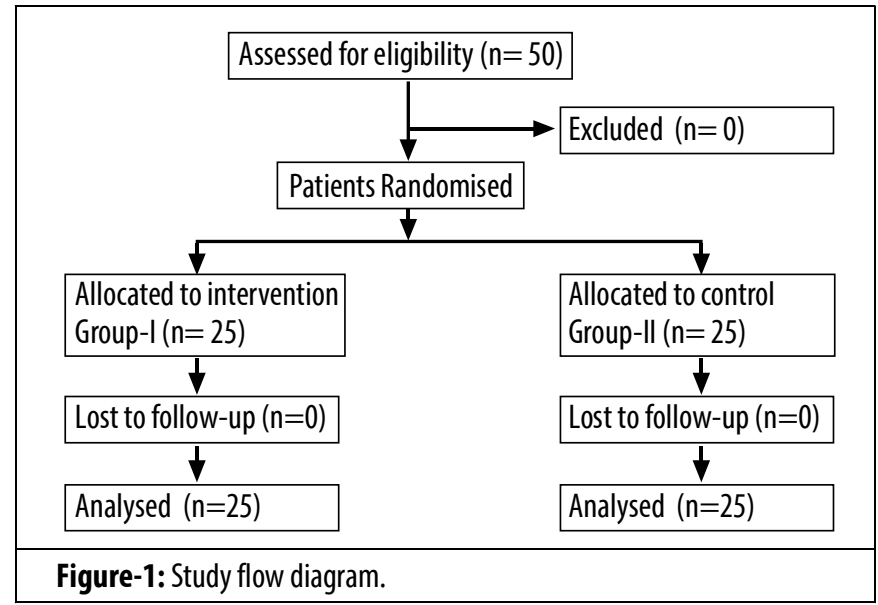

Prior to LMA removal in group-I, isoflurane MAC awake (MAC less than or at 0.4) was achieved in end-expiratory gases with $60 \%$ nitrous oxide and $40 \%$ oxygen. Thereafter, propofol $1 \mathrm{mg} / \mathrm{kg}$ was administered to maintain deep anaesthesia state for LMA removal. In group-II, the deep anaesthesia state was maintained by an end-expiratory isoflurane 1.2 MAC with $60 \%$ nitrous oxide and $40 \%$ oxygen. In both the groups, LMA was removed with inflated cuff, throat was suctioned and patients were turned into the lateral recovery position. Isoflurane and nitrous oxide were turned off and 100\% oxygen was supplemented till the patient had regained consciousness. All patients were transported to the PostAnaesthesia Care Unit (PACU), once airway patency and peripheral oxygen saturation (Sp02) >95\% was ensured on room air. Children were allowed to wake up on their own in PACU at 5L/minute of oxygen via Hudson mask.

A self generated proforma was used to record demographics, type of surgeries, surgical and anaesthesia duration, LMA insertion attempts and primary outcome, airway obstruction (noisy or stridor breathing) requiring jaw support, laryngospasm, bronchospasm, retching and vomiting. Primary outcome elements noted were adverse airway events, such as coughing, bucking, hypersalivation, and oxygen desaturation (Sp02<90\%). The adverse airway events were observed for 15 minutes after LMA removal. The secondary outcome was the emergence time duration and PACU stay duration. SPSS 19 was used for data analysis. Relevant descriptive statistics, frequencies and percentages were computed for categorical variables, including gender, ASA status, number of LMA insertion attempts, mode of analgesia and type of surgery.Mean \pm standard deviation (SD) was 
computed for normally distributed quantitative variables and analysed by independent sample t-test. The median (interquartile range [IQR]) were reported for non-normal distribution and analysed by Mann Whitney $U$ test. ChiSquare test and Fisher exact test were used to compare the difference between the groups for adverse airway events, teeth clenching, airway obstruction, laryngospasm, bronchospasm, retching, and vomiting. $\mathrm{P}<0.05$ was considered statistically significant.

\section{Results}

Of the 50 patients, there were $25(50 \%)$ in each of the two groups. Overall, there were $46(92 \%)$ males and $4(8 \%)$ females. There was no significant difference in demographic and baseline vitals between the groups (Table 1).

LMA insertion on first attempt was $25(100 \%)$ in groupI and 24(96\%) in group-II. There were no differences in the type of surgeries, surgical duration and anaesthesia duration between the groups (Table 2).

The incidence of coughing and bucking was $4(16 \%)$ in group-II and $1(4 \%)$ in group-l. Hyper-salivation was observed in $3(12 \%)$ patients in group-II and $4(16 \%)$ in group-I. Hypoxia 2(8\%) and laryngospasm 1(4\%) were seen in group-II only. Teeth clenching in group-II was $7(28 \%)$ versus $1(4 \%)$ in group-I, and airway obstruction in group-Il was $9(36 \%)$ versus $3(12 \%)$ in group-I. Both values were statistically significant in group-II (Table 3 ).

Emergence timing was significantly shorter in group-I

Table-1: Comparison of demographics and baseline vital parameters between groups.

\begin{tabular}{lccc}
\hline Variables & $\begin{array}{c}\text { Group-I } \\
\mathbf{n = 2 5}\end{array}$ & $\begin{array}{c}\text { Group-II } \\
\mathbf{n = 2 5}\end{array}$ & $\boldsymbol{p}$-values \\
\hline Age (Years) $\dagger$ & $4.2(3.5)$ & $3.1(3)$ & 0.31 \\
Weight $(\mathrm{kg}) \dagger$ & $15.5(6.8)$ & $13.7(5.3)$ & 0.28 \\
Height $(\mathrm{cm}) \dagger$ & $106(20)$ & $94.5(15)$ & 0.05 \\
Gender & & & \\
Male & $24(96 \%)$ & $22(88 \%)$ & 0.61 \\
Female & $1(4 \%)$ & $3(12 \%)$ & \\
ASA Status & & & \\
I & $17(68 \%)$ & $22(88 \%)$ & 0.08 \\
II & $8(32 \%)$ & $3(12 \%)$ & \\
Heart Rate (bmp) & $115.7 \pm 13.9$ & $117.36 \pm 19.9$ & 0.73 \\
Systolic Blood Pressure (mmHg) & $92.1 \pm 11.2$ & $91.2 \pm 8.8$ & 0.74 \\
Diastolic Blood Pressure (mmHg) & $47.7 \pm 9.0$ & $46.6 \pm 9.4$ & 0.65 \\
Respiratory Rate & $21.2 \pm 3.3$ & $22.6 \pm 3.5$ & 0.16 \\
\hline
\end{tabular}

Results are presented as tmedian (interquartile range [IQR]), compared with the Mann Whitney $\mathrm{U}$ test; mean \pm standard deviation, compared with t-test and $\mathrm{n}(\%)$, compared with chi-square or Fisher exact test. ASA: American Society of Anaesthesiologists.

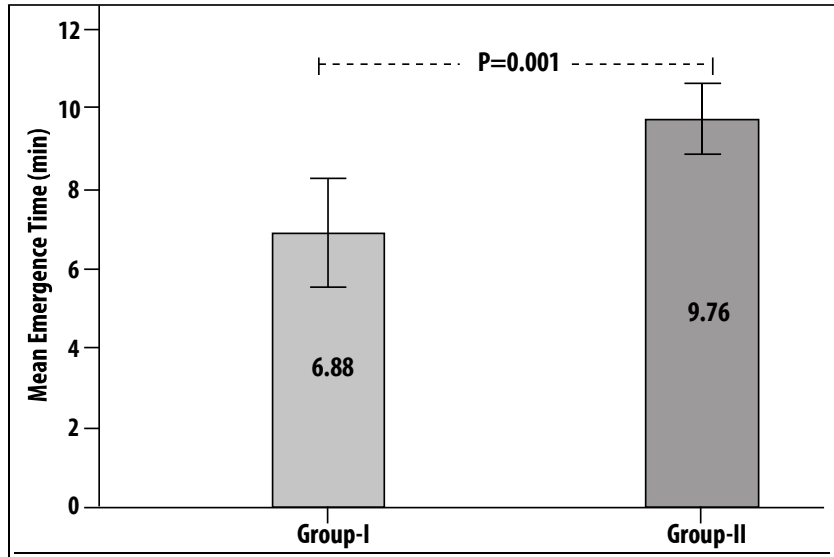

Figure-2: Comparison of mean emergence time duration between the groups.

Table-2: Comparison of LMA insertion attempts, surgery duration, anesthesia duration and type of surgeries between study groups.

\begin{tabular}{lccc}
\hline Variables & $\begin{array}{c}\text { Group-I } \\
\mathbf{n}=\mathbf{2 5}\end{array}$ & $\begin{array}{c}\text { Group-II } \\
\mathbf{n}=\mathbf{2 5}\end{array}$ & p-values \\
\hline LMA Insertion attempts & & & \\
1 & $25(100 \%)$ & $24(96 \%)$ & 0.99 \\
2 & $0(0 \%)$ & $1(4 \%)$ & \\
Duration of surgery (min) $\dagger$ & $35.5(16)$ & $28.5(23)$ & 0.21 \\
Duration of anaesthesia (min) $\dagger$ & $59(23)$ & $59(21)$ & 0.37 \\
Type of surgery & & & 0.43 \\
Circumcision & $12(48 \%)$ & $10(40 \%)$ & \\
Inguinal Hernia & $6(24 \%)$ & $7(28 \%)$ & \\
PPV Ligation & $3(12 \%)$ & $3(12 \%)$ & \\
Hypospadias Repair & $1(4 \%)$ & $5(20 \%)$ & \\
Circumcision and Inguinal Hernia & $1(4 \%)$ & $0(0 \%)$ & \\
Inguinal Hernia and Meatotomy & $1(4 \%)$ & $0(0 \%)$ & \\
Urethro cutaneous fistula repair & $1(4 \%)$ & $0(0 \%)$ & \\
\hline
\end{tabular}

Results are presented as tmedian (interquartile range [IQR]), Mann Whitney $\mathrm{U}$ test; mean \pm standard deviation t-test; $n$ (\%), chi-square or Fisher exact test. ${ }^{*} p<0.05$.

LMA: Laryngeal mask airway PPV: Patent processus vaginalis

Table-3: Comparison of adverse airway events between groups.

\begin{tabular}{|c|c|c|c|c|}
\hline Adverse Airway Event & $\begin{array}{c}\text { Group-I } \\
n=25\end{array}$ & Group-II & $\begin{array}{c}\text { Diff (95\%Cl) } \\
n=25\end{array}$ & $\overline{p \text {-values }}$ \\
\hline Cough & $1(4 \%)$ & $4(16 \%)$ & $\begin{array}{c}12 \% \\
{[-4.3 \% \text { to } 28.3 \%]}\end{array}$ & 0.34 \\
\hline Mild & 1 & 3 & & \\
\hline Moderate & 0 & 1 & & \\
\hline Severe & 0 & 0 & & \\
\hline Bucking & $0(0 \%)$ & $4(16 \%)$ & $\begin{array}{c}16 \% \\
{[-1.6 \% \text { to } 30.4 \%}\end{array}$ & 0.11 \\
\hline $\begin{array}{l}\text { Oxygen desaturation } \\
(<90 \%)\end{array}$ & $0(0 \%)$ & $2(8 \%)$ & $\begin{array}{c}8 \% \\
{[-2.6 \text { to } 18.6 \%}\end{array}$ & 0.49 \\
\hline Hyper-salivation & $4(16 \%)$ & $3(12 \%)$ & $\begin{array}{c}-4 \% \\
{[-23.2 \% \text { to } 15.2 \%]}\end{array}$ & 0.99 \\
\hline Teeth Clenching & $1(4 \%)$ & $7(28 \%)$ & $\begin{array}{c}24 \% \\
{[4.8 \% \text { to } 43.2 \%]}\end{array}$ & $0.05^{*}$ \\
\hline $\begin{array}{l}\text { Airway Obstruction } \\
\text { requiring Jaw support }\end{array}$ & $3(12 \%)$ & $9(36 \%)$ & $\begin{array}{c}24 \% \\
{[1.3 \% \text { to } 46.7 \%]}\end{array}$ & $0.047^{*}$ \\
\hline Laryngospasm & $0(0 \%)$ & $1(4 \%)$ & $\begin{array}{c}4 \% \\
{[-3.7 \% \text { to } 11.7 \%}\end{array}$ & 0.99 \\
\hline
\end{tabular}

Results are presented $\mathrm{n}(\%)$, chi-square or Fisher exact test. 
than group-II ( $p=0.001)$ (Figure 2). Duration of recovery room stay was almost similar in both groups $(p=0.74)$. Bronchospasm, retching and vomiting were not reported in either of the two groups.

\section{Discussion}

The major finding of the current study is the reduction of coughing, bucking, teeth clenching and airway obstruction in group-I, which had LMA removal at isoflurane $0.4 \mathrm{MAC}$ awake plus propofol $1 \mathrm{mg} / \mathrm{kg}$, compared to group-II, which had isoflurane at 1.2 MAC alone. In addition, there was minimal wake-up time in group-I.

The focal point of the study was to explore a safe method for LMA removal by overcoming the existing challenges, like airway obstruction, aspiration risk, emergence and PACU time duration. We compared LMA removal by two different deep anaesthesia techniques; deep isoflurane MAC $1.2^{12}$ versus a combination of propofol $1 \mathrm{mg} / \mathrm{kg}$ with isoflurane 0.4 MAC awake. Confounding factors, such as induction and maintenance of anaesthesia, were standardised. Analgesia was achieved with caudal block and none of the patients required rescue analgesia. The age groups ( 3.1 years in group-II and 4.2 years in groupI) were proponents for the development of emergence complications. ${ }^{13}$

In a study, ${ }^{5}$ children developed severe airway hyperreactivity in which LMA was removed under awake isoflurane anaesthesia. Six out of 30 patients in deep isoflurane LMA removal group required manual jaw support. 5 In contrast, 3 out of 25 children in our deep propofol isoflurane group required jaw support and 9 out of 25 children needed jaw support in the deep isoflurane group. However, we noticed a significant difference in patient's emergence time duration, the 6.88 minutes in our deep propofol-isoflurane group and 9.76 minutes in deep isoflurane group which is comparably lower than the earlier reported deep isoflurane emergence time duration of 19 minutes and 11 minutes of awake isoflurane group. ${ }^{5} \mathrm{~A}$ study ${ }^{13}$ on LMA removal under sevoflurane anaesthesia reported that the patients' awakening time was similar in deep and awake sevoflurane anaesthesia. Our study's combined propofolisoflurane group's awakening time duration was almost similar, but the incidence of adverse airway events was much lesser than the study groups in the earlier study. ${ }^{13}$ The current study failed to detect the time differences between the groups for the recovery room stay duration, as the departmental policy confined ASA-I and II patients for 45 minutes of PACU stay. We preferred low-dose propofol with isoflurane to obtain the deep anaesthesia state for LMA removal. Propofol is a potent inhibitor of airway reflexes at the hypnotic dosage and it is wellknown for the prevention of emergence complications in children at sub-hypnotic concentrations. 14

The current study has its limitations. lisoflurane MAC reduction to a pre-determined level and propofol addition in the study group were impractical for blinding purposes. However, an independent observer in the operating room and in the recovery room was assigned to collect data. Besides, pain score was not recorded that could have interrupted sensorium. Nevertheless the caudal was the sole analgesia and none of the patients requested rescue analgesia. Also, Dixon's method ${ }^{15}$ was not applied; fixed isoflurane MAC might have caused variation in anaesthesia depth among the subjects. Moreover, propofol dose of $1 \mathrm{mg} / \mathrm{kg}$ was administered that is relatively higher than the reported sub-hypnotic dose of $0.5-0.8 \mathrm{mg} / \mathrm{kKg} ;{ }^{16}$ nevertheless, the propofol group awakening time was shorter in our study. Finally, oral surgery 17 (dental, otolaryngologic) has direct airway involvement and was excluded from the current study.

Further studies could be considered with larger sample size, replacement of isoflurane with sevoflurane and the use of propofol at lower doses.

\section{Conclusion}

Deep LMA removal in paediatric patients by a combination of low-dose propofol with isoflurane MAC awake reduced adverse airway events and minimised the emergence time duration in children. This method can be considered as an alternative to deeper plane of isoflurane anaesthesia.

\section{References}

1. Frediami M, Blanchini G, Capanna M, Casini L, Costa M, Uggeri S, et al. [The laryngeal mask in pediatric anesthesia]. Minerva Anesthsiol 1996; 62: 65-7.

2. Brain Al. The laryngeal mask: a new concept in airway management. Br J Anaesth 1983; 55: 801-5.

3. Thomas-Kattappurathu GI, Kasisomayajula A, Short J. Best position and depth of anesthesia for laryngeal mask airway removal in children: A randomized controlled trial. Eur J Anaesthesiol 2015; 32: 624-30.

4. Lee JR, Kim SD Kim CS, Yoon TG, Kim HS. Minimum alveolar concentration of sevoflurane for laryngeal mask airway removal in anesthetized children. Anesth Analg 2007; 104: 528-31. 
5. Pappas Al, Sukhani R, Lurie J, Pawlowski J, Sawick K, Corsino A Severity of airway hyperreactivity associated with laryngeal mask airway removal: correlation with volatile anesthetic choice and depth of anesthesia. J Clin Anaesth 2001; 13: 498-503.

6. Nunez J, Hughes J, and Wareham K, Asai T. Timing of removal of laryngeal mask airway. Anesthesia 1998; 53:126-30.

7. Samarkandi AH. Awake removal of the laryngeal mask airway is safe in pediatric patients. Can J Anaesth 1998; 45: 150-2.

8. Splinter WM, Reid CW. Removal of the laryngeal mask airway in children: deep versus awake. J Clin Anesth 1997; 9: 4-7.

9. Baird MB, Mayor AH, Goodwin AP. Removal of the laryngeal mask airway: factors affecting the incidence of postoperative adverse respiratory events in 300 patients. Eur J Anaesthesiol 1999; 16: 251-

10. Heidari SM, Abbasi S, Rahimi M. Removal of Laryngeal Mask Airway: Awake or Deep Anesthesia. J Res Med Sci 2005; 10: 59-62.

11. Kitching AJ, Walpole AR, Blogg CE. Removal of the laryngeal mask airway in children: anesthetized compared with awake. Br J Anaesth 1996; 76: 874-6.

12. Nickalls RW, Mapleson WW. Age-related iso-MAC charts for isoflurane, sevoflurane, and desflurane in man. $\mathrm{Br} J$ Anaesth 2003 91: 170-4.

13. Park JS, Kim KJ, Oh JT, Choi EK, Lee JR. A randomized controlled trial comparing Laryngeal Mask Airway removal during adequate anesthesia and after awakening in children aged 2 to 6 years. J Clin Anaesth 2012; 24: 537-41.

14. Huang RC, Hung NK, Lu CH, Wu ZF. Removal of Laryngeal Mask Airway in Adults Under Target-Controlled, Propofol-Fentanyl Infusion Anesthesia: Awake or Deep Anesthesia? Medicine (Baltimore) 2016; 95: e3441.

15. Xiao WJ, Deng XM, Tang GZ, Lu MP, Xu KL. Caudal anesthesia reduces the minimum alveolar concentration of enflurane for laryngeal mask airway removal in boys. Can J Anaesth 2002; 49: 194-7.

16. Afshan G, Chohan U, Qamar-UL-Hoda M, Kamal RS. Is there a role of a small dose of propofol in the treatment of laryngeal spasm? PaediatrAnaesth 2002; 12: 625-8.

17. Ramgolam A, Hall GL, Zhang G, Hegarty M, Von Ungern-Sternberg BS. Deep or awake removal of laryngeal mask airway in children at risk of respiratory adverse events undergoing tonsillectomy-a randomized controlled trial. Br J Anaesth 2018; 120: 571-80. 